\title{
XLIX. The dielectric capacity of atoms
}

\section{William Sutherland}

To cite this article: William Sutherland (1904) XLIX. The dielectric capacity of atoms, Philosophical Magazine Series 6, 7:40, 402-405, DOI: 10.1080/14786440409463134

To link to this article: http://dx.doi.org/10.1080/14786440409463134

曲 Published online: 15 Apr 2009.

6 Submit your article to this journal $\pi$

Џll Article views: 5

Q View related articles $₫$ 
Thus the increase in volume of the bulb is

$$
\begin{aligned}
\delta v & =\pi a^{2} l p_{0} \times \frac{4 \cdot 4 \times(70)^{3}}{32 \times 6 \times 10^{11}} \\
& =\pi a^{2} l p_{0} \times 7800 \times 10^{-11} .
\end{aligned}
$$

The compressibility of water is about $4 \times 10^{-11}$, so that the diminution of volume of the fluid under a hydrostatic pressure is

$$
\delta v_{0}=\pi a^{2} l p_{0} \times 4 \times 10^{-11} .
$$

The expansion of the glass vessel under the stresses of electrical type is far more important than the contraction of the fluid under the hydrostatic pressure of Mr. Walker's theory. I therefore think that, so far from being crucial, Quincke's experiment gives no support to the latter theory, and can be readily explained by the stresses of electrical type.

Physical Laboratory, Glasgow.

December 12, 1903.

XL1X. The Dielectric Capacity of Atoms. By William Sutherland *.

$7 \mathrm{TE}$ electron theory imparts more interest than ever to the investigation of the properties of atoms. At the present stage of this theory the electrical properties of atoms demand investigation from every possible point of attack. The dielectric capacity of the atom being the most fundamental of such properties, it seemed to me desirable to investigate it by means of certain principles developed in a paper on "Ionization, Ionic Velocities, and Atomic Sizes" (Phil. Mag. [6] iii. Feb. 1902). In that paper it was shown that at infinite dilution the ionic velocity ${ }_{1} \lambda_{0}$ of an element 1 whose atom has a radius $a_{1}$ and a dielectric capacity $K_{1}$ dissolved in a solvent whose viscosity is $\boldsymbol{\eta}$ and dielectric (apacity $\mathrm{K}_{0}$ is given by the equation

$$
{ }_{1} \lambda_{0}=v e^{2} \mathrm{~K}_{0} / 6 \pi \eta a_{1} \mathrm{~K}_{1} \text {, . . . . . }
$$

where $\nu$ is the valency of the ion and $e$ is the electric charge of a monovalent ion. In seeking to verify this relation by means of published experimental data, in the absence of measured values of $K_{1}$ the dielectric capacity of the stuff' of

* Communicated by the Author. 
the atom, I used Maxwell's relation $K_{1}=N_{1}^{2}$, where $N_{1}$ is the refractive index of the stuff of the atom. For ten metallic ions, namely those of the Li family, those of the Be family from $\mathrm{Mg}$ to $\mathrm{Ba}$, and for $\mathrm{Zn}$, and for the six negative fatty acid radicals from formic to caproic, the equation (16) wis found to be verified in a broad way. But in the case of the halogens from $\mathbf{F}$ to $I$ the relation seemed to break down completely, as also in the case of the ions $\mathrm{H}$ and $\mathrm{OH}$. $\mathrm{By}$ means of further data $I$ have found that $C d$ ranges itself with the metals mentioned, while $\mathrm{Ag}$ and $\mathrm{Pb}$ rank as further exceptions. In the case of the halogens it was suggested that, as their atoms are heptad as well as monad, we must imagine each halogen to have associated witl it four negative electrons and three positive ones. Three of the negative electrons unite with the positive ones when the halogen atom acts as a monad, and so form inside the halogen atom three electric donblets. With a notation which I have proposed this idea would be expressed by writing the following as the formula for the $\mathrm{Cl}$ ion : $\mathrm{bCl}((\$))_{3}$. In this way we ean briefly record the fact that $\mathrm{Cl}$ is a monad with heptad capabilities. Now, if the three electric doublets \#b inside the halogen ion produce an abnormal effect on the propagation of light through the halogen ion, we shall not be justified in using Maxwell's relation for finding the dielectric capacity from the refractive index. Just as water and a number of similar substances have two limiting dielectric capacities, namely 80 and 2 in the case of water, with every intermediate value for electric alternations of suitable frequency, so it seems to me that the halogen atoms have a dielectric capacity $\mathrm{K}_{\mathrm{r}}$ which is different from $\mathrm{N}_{1}{ }^{2}$ for the conditions under which their ionic velocities are measured. Accordingly I propose to use equation (16) for finding the dielectric capacities of the halogen atoms and of atoms in general. By means of the data given on page 175 of the paper mentioned and the assumption that $K_{1}=N_{1}{ }^{2}$ on the average for the regular ions, the equation becomes one for $K_{1}$ in the following form :

$$
\mathrm{K}_{1}=280 \mathrm{v} / \mathrm{\lambda}_{0} \mathrm{~B}^{\frac{1}{3}}, \quad . \quad . \quad . \quad . \quad . .
$$

where $\mathrm{B}$ is the volume of a gramme-atom of the ion.

The following table contains the values of the ionic velocities given by Kollrausch except for $\mathrm{Cd}$ and $\mathrm{Pb}$, the values of B taken from "Further Studies on Molecular Force" (Phil. Mag. [5] xxxix.), and also the values of $K_{1}$ calculated by (17), using for $v$ the value 1 for the monad atoms and 2 
for the dyads. In the last row of the table are given the values of $10 \mathrm{~K}_{1} \mathrm{~B}^{\frac{1}{2}} / v$, to be discussed immediately.

\begin{tabular}{|c|c|c|c|c|c|c|c|c|c|}
\hline & $\begin{array}{l}\mathrm{Li} . \\
355\end{array}$ & $\begin{array}{l}\text { Na. } \\
44 \cdot 4\end{array}$ & $\begin{array}{c}\mathrm{K} . \\
65 \cdot 3\end{array}$ & $\begin{array}{l}\mathrm{Rb} . \\
67 \cdot 3\end{array}$ & $\begin{array}{l}\text { Cs. } \\
67.8\end{array}$ & $\begin{array}{c}\mathbf{M g} . \\
48\end{array}$ & $\begin{array}{l}\text { Ca. } \\
53\end{array}$ & $\begin{array}{l}\text { Sr. } \\
54\end{array}$ & $\begin{array}{c}\mathrm{Bn} . \\
57 \cdot 3\end{array}$ \\
\hline & 2 & $7 \cdot 4$ & 18.6 & $34 \cdot 4$ & 56 & $5: 6$ & $8 \cdot 6$ & 106 & $16 \cdot 6$ \\
\hline & 6.27 & $3 \cdot 24$ & 1.62 & 1.28 & $1 \cdot 08$ & 6.58 & $5 \cdot 16$ & $4 \cdot 72$ & 3.88 \\
\hline $10 K_{1} B$ & & & 70 & 75 & 81 & 78 & 76 & 77 & 78 \\
\hline
\end{tabular}

\begin{tabular}{|c|c|c|c|c|c|c|c|}
\hline $\begin{array}{l}\mathrm{Zn} . \\
\ldots \ldots \ldots . \\
4 \pi \cdot 5\end{array}$ & $\begin{array}{l}\mathrm{Cdl} \\
525\end{array}$ & $\begin{array}{l}\text { Ag. } \\
557\end{array}$ & $\begin{array}{l}\mathrm{Pb} . \\
55\end{array}$ & $\begin{array}{l}\text { F. } \\
46 \cdot 1\end{array}$ & $\begin{array}{l}\mathrm{Cl} \\
65.9\end{array}$ & $\begin{array}{l}\mathrm{Br} . \\
675\end{array}$ & $\begin{array}{l}1 . \\
667\end{array}$ \\
\hline$\ldots \ldots \ldots \ldots, 10 \cdot 6$ & $12 \cdot 5$ & $6 \cdot 8$ & $9 \cdot 8$ & 9 & 19 & 20 & 36 \\
\hline$\ldots \ldots .530$ & $4 \cdot 60$ & $2 \cdot 66$ & 459 & 2.92 & $15 ! 9$ & $1 \cdot 40$ & 1 \\
\hline $10 \mathrm{~K}_{1} \mathrm{~B}^{\frac{1}{2}} / \nu \ldots 87$ & 82 & 70 & 72 & 88 & 70 & 71 & 76 \\
\hline
\end{tabular}

In the case of the halogens it is interesting to compare the values of the dielectric capacity thus derived with the values of $\mathrm{N}_{1}{ }^{2}$, thus

$\begin{array}{ccccc} & \text { F. } & \mathrm{Cl} & \mathrm{Br} . & \mathrm{I} \\ \mathrm{N}_{1}{ }^{2} \ldots \ldots \ldots \ldots \ldots \ldots & 1.34 & 2 \cdot 43 & 2 \cdot 2 & 310 \\ \mathrm{~K}_{1} \ldots \ldots \ldots \ldots \ldots \ldots & 2.92 & 159 & 1 \cdot 40 & 1 \cdot 27\end{array}$

A study of those values shows that in the halogen atoms $\mathrm{K}_{1}$, instead of being equal to $\mathrm{N}_{1}^{2}$, varies inversely as $\mathrm{N}_{1}{ }^{2}$.

Returning to the main table, we find that $\mathrm{K}_{1} \mathrm{~B}^{2} / \nu$ is constant without a single marked exception, although the halogens have just been shown to be so exceptional in regard to Maxwell's law. We have therefore this result, that the dielectric capacity of an atom is directly proportional to the valency and inversely proportional to the square root of the volume of the atom. It is interesting to find that valency, which Faraday proved to be of fundamental importance in bis electrolytic law, is of similar importance in connexion with dielectric capacity, that predominating electric property of matter which Faraday discovered. As to the physical signification of our law for $K_{1}$, it seems that it may be sought by the foliowing short train of speculation. I have shown that cohesion can be traced to the mutual attractions of the electric doublets in molecules acting like minute magnets. Thus cohesion is an electrical phenomenon. By following out a similar train of reasoning it can be shown that rigidity in solids is a mechanical result of the electric doublets in the molecules. At absolute zero the rigidity is equal to the electric energy of these doublets per unit volume. But to express this electric energy we must regard it as proportional 
to the square of an electric quantity associated with the molecule. Thus rigidity is proportional to the square of an electric quantity. Now our law for the dielectric capacity of an atom means that the square of $\mathrm{K}_{1} / v$ for an atom when multiplied by the volume of the atom is the same for all. It seems, then, as though a certain stock of electric energy associated with the electrons in an atom were the same for all atoms. The law for $\mathbf{K}_{1}$, then, seems to be of a similar nature to that of Dulong and Petit and of the fundamental law of molecular physics which makes the kinetic energy of translation of all molecules at a given temperature the same.

But to return from speculation to the immediate bearings of the formula $\mathrm{K}_{1} \mathrm{~B}^{\frac{1}{2}} / \nu=$ constant; we find that in (16) it makes the ionic velocity of an atom directly proportional to the sixtl root of the volume of the atom-that is to say, to the square root of its radius. This brings out neatly the old paradox about ionic velocities. Hitherto it bas been assumed that the ionic velocities have all been measured with the same driving force for all ions. The result that a large ion like that of $\mathrm{K}$ travels faster than a small one like that of $\mathrm{Li}$ under the same driving force in a resisting medium is, indeed, puzzling until, in taking account of the dielectric capacity of the atom, we see that the driving forces assumed equal are in reality not so at all.

Melbourne, December 1903.

\section{The Crémicu-Pender Discovery.} $B_{y}$ Wililam Sutherland*.

TN the experiments carried out by the happy collaboration of Messrs. Crémieu and Pender (Phil. Mag. Oct. 1903) practically the whole of the difficulty in reconciling the apparently contradictory results obtained by Rowland and his pupils and Röntgen, Himstedt, and others on the one hand, and by Crémieu on the other, concerning the magnetic effects of electric convection was traced to the one fact that Crémieu covered his metallic electrified surfaces with soiid dielectric. The solid dielectric rotating with the revolving charged metallic disk reduces the magnetic effect considerably, so as in some experiments to make it appear to ranish. The combined experiments have brought into prominence a fundamental property of dielectrics. Now exactly the same property made itself apparent in my theoretical

* Communicated by the Authol. 